\title{
O Serviço Social uruguaio e suas bases críticas
}

\section{The Uruguayan Social Work and its critical bases}

\author{
José Fernando Siqueira da Silva ${ }^{a}$ \\ (- http://orcid.org/0000-0003-1040-9558 \\ José Pablo Bentura ${ }^{b}$ \\ (D) http://orcid.org/0000-0003-2341-4751
}

\begin{abstract}
Resumo: Este artigo tem por objetivo debater a gênese, o desenvolvimento e a consolidação da fração mais crítica do Serviço Social no Uruguai. Produto de estudo pós-doutoral realizado na Universidade da República e financiado pela Fapesp em 2020, o texto aborda os elementos centrais que sustentaram a formação de um Serviço Social progressista a partir das lutas latino-americanas coletivamente travadas nas décadas de 1960, 1970 e 1980, e o fim da ditadura cívico-militar no Uruguai em 1985.
\end{abstract}

Palavras-chaves: Serviço Social Uruguaio. Tendências Críticas. América Latina.

\begin{abstract}
This article aims to discuss the genesis, development and consolidation of the most critical fraction of Social Work in Uruguay. Product of a postdoctoral study conducted at the University of the Republic and funded by Fapesp in 2020, the text addresses the central elements that sustained the formation of a progressive Social Work from the Latin American struggles collectively fought in the 1960s, 1970 s and 1980s, and the end of the civicmilitary dictatorship in Uruguay from 1985.
\end{abstract}

Keywords: Uruguayan Social Work. Critical Trends. Latin America. 


\section{Observações iniciais}

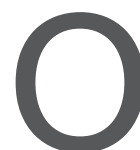

texto ora apresentado é produto de estudo realizado no ano de 2020 durante uma instância pós-doutoral de 11 meses na Universidad de La República (Udelar-Uruguai). Circunscrito ao limite de páginas estabelecido para a submissão deste manuscrito, as páginas que se seguem analisam, resumidamente, aqueles elementos que determinaram a gênese, o desenvolvimento e a consolidação da fração mais crítica do Serviço Social nesse país. A pesquisa, sistematizada pelo docente-pesquisador, contou com o apoio da Fapesp (processo 2019/10340-0) e a contribuição de seu tutor que divide a autoria deste texto.

\section{O Uruguai e suas particularidades na América Latina}

A trajetória do Uruguai reafirmou a tradição dependente (Fernandes, 2009; Marini, 2008; Katz, 2020), cuja base econômica é predominantemente agroexportadora e constituída por grupos econômicos que têm interesses voltados para fora do país. Sua formação social foi marcada pela forte participação de trabalhadores imigrantes europeus (Acosta, 2005, p. 27-28), embora tenha convivido com formas arcaicas de produção de perfil oligárquico, com o trabalho escravo (seguramente mais tímido se comparado com outras regiões da América Latina) e com a penetração do capital monopolista (particularmente nas primeiras décadas do século $\mathrm{XX}$ ). Reafirmou, assim, por caminhos diversos, sua face primário-exportadora, sem o desenvolvimento de indústrias produtoras de bens, mas com investimentos internacionais que paulatinamente modernizaram setores estratégicos para a exportação do país, tais como a indústria frigorífica.

A economia uruguaia não se constituiu num modelo de economia conhecido na América Latina como de "enclave", ou seja, não se sustentou substancialmente - como nos casos brasileiro, mexicano e argentino (guardadas as diferenças desses processos) - na atração massiva de recursos externos para o investimento na indústria local, mesmo porque 
o mercado interno uruguaio sempre foi pouco atrativo. Portanto, consolidou-se uma economia "voltada para fora", mas com uma base econômica cuja propriedade era "nacionalmente controlada" (Real de Azua, 1984, p. 93-94). Sob essas bases se formou o tradicional sistema bipartidário dividido entre o Partido Colorado ("colorados") e o Partido Nacional ("blancos”), que persistiu até 1971 com a fundação da Frente Ampla, com forte capacidade de absorver diversas demandas sociais, acomodar interesses de classes e de seus diversos segmentos, bem como de se articular com heterogênea tradição caudilha e populista (Real de Azua, 1984, p. 92).

O Uruguai possui forte tradição republicano-liberal, posteriormente adensada por uma perspectiva republicano-democrática mais radical e bastante peculiar, sobretudo a partir do primeiro batllismo (1903-1931). Isso impactou substancialmente a sociedade uruguaia desde muito cedo, processo também influenciado pela busca de uma identidade nacional marcada pelo vazio interiorano e pela presença constante de fronteiras com dois gigantes latino-americanos: Brasil e Argentina. Os estudos de Gerardo Caetano (2015) revelam aspectos de uma sociedade cujas tensões estruturais foram amortecidas (nos termos de Real de Azua, 1984):

a) certo tipo de cidadania "hiperintegradora", ainda que também tenha reproduzido a tradicional divisão campo/cidade;

b) a tentativa de disputar o discurso e a prática liberal, no campo republicano explícito;

c) a ênfase em reformas cívicas (nação/cidadania) e políticas (expressas no formalismo constitucional), processo consolidado na relação entre parlamento e cidadãos;

d) a "reforma moral" e sua consequência explicitamente laica e avançada, que também contou com uma tradição espanhola menos incidente (mais tardia) nas bandas orientais se comparada com outras regiões colonizadas;

e) uma educação pública igualmente laica e absolutamente prematura para os padrões latino-americanos, o que implicou a criação 
da escola primária na segunda metade do século XIX por meio da Lei da Educação comum (1877), proposta pelo então Diretor de Instrução Pública, José Pedro Varela, durante a ditadura do Coronel Lorenzo Latorre.

f) a influência explícita de valores e ideias francesas a partir do final do século XIX, de base republicana, iluminista, de apoio à ciência e às artes, com nítida separação entre Estado e igreja. Essa orientação se expressou, por exemplo, nas proposições de importantes quadros intelectuais situados entre o final do século XIX e as primeiras décadas do século XX, tais como Carlos Vaz Ferreira (um republicano liberal) e José Enrique Rodó (um positivista convicto), ambos com forte ascendência greco-latina e representantes do "pensamento vivo da filosofia uruguaia" (Acosta, 2005, p. 42-47). Um pensamento essencialmente plural, por vezes eclético, bem como uma prática pragmático-científica, de base liberal.

g) a relativa marginalidade dos setores militares absorvidos originalmente pela força partidária, pela orientação republicana e pela mobilização de setores sociais.

A importância do primeiro batllismo na sociedade uruguaia é indiscutível. Essa tendência, comandada pelo Partido Colorado, marcou profundamente o Uruguai nos primeiros 30 anos do século XX. Antecedeu a crise do capital de 1929, a revolução bolchevique de 1917 e a Primeira Guerra Mundial, bem como se formou antes do Estado de Bem-Estar Social keynesiano. ${ }^{1}$ O reformismo batllista insistiu na construção de um país sólido-pequeno, industrial, moderno, modelo na proteção social aos mais fracos, atrativo à mão de obra externa e alternativa econômica e social a Buenos Aires.

Além dos dois governos de José Batlle y Ordóñez (1903-1907 e 1911-1915), o pleno domínio Colorado se sustentou em outros governos: Claudio Williman (1907-1911), Feliciano Viera (19151919), Baltasar Brum (1919-1923), José Serrato (1923-1927) e Juan Campisteguy (1927-1931). 
As reformas sociais - sempre tensionadas pela classe operária se concentraram em algumas áreas estratégicas: ${ }^{2}$ a) assistência pública; b) ensino leigo gratuito e obrigatório para o primeiro nível; c) jornada de trabalho de oito horas diárias (1915); d) lei do descanso semanal (1920); e) sistema de aposentadorias, tais como as caixas de empregados/operários de serviços públicos (1919) e organização previdenciária de trabalhadores de bancos (1925). É significativo, ainda, ressaltar a lei do divórcio a partir da vontade da mulher (1913), bem como o adensamento e a ampliação de cursos oferecidos pela Universidade da República com participação direta de estudantes. ${ }^{3}$ Vale destacar que é nesse momento (1927) que o Serviço Social tem sua gênese no país articulada às atividades desempenhadas pelas “Visitadoras Sociales de Higiene" (Ortega, 2008, p. 48).

A crise mundial de 1929 impactou o Uruguai, mas não foi suficiente para derrotar o Partido Colorado que vinha historicamente ocupando o poder executivo nacional. O governo de Gabriel Terra, eleito em 1930 e empossado em 1931, incapaz de lidar com as tensões impostas e com os efeitos econômicos perversos de 1929, transformou-se em uma ditadura em 1933. Conforme destaca Real de Azua (1984, p. 65), foram evocados históricos argumentos fartamente utilizados por setores mais conservadores: excesso dos gastos públicos, carga fiscal pesada, déficit da balança comercial, a ruína da produção agrária aprofundada pela crise de 1929, os tradicionais apelos anticomunistas, o excesso de greves caracterizadas como anarquistas, o perigo tradicionalmente atribuído a esses eventos, além de farta repressão a estudantes, a políticos de esquerda, a dirigentes sindicais, entre outros setores de oposição.

O ímpeto reformista do primeiro battlismo será mantido no neobatllismo, acrescido de uma política industrial mais intensa. Essa

2 Como referências para este debate, consultar Caetano (2015) ou Acosta (2005). A organização operária uruguaia e suas primeiras greves foram diretamente influenciadas por imigrantes franceses e espanhóis, movimentos inspirados na Comuna de Paris de 1871 e na Revolução Cantonalista de 1873, de inspiração anarquista.

3 A fundação da Universidade da República deu-se entre 1833 e 1849. A Federação de Estudantes Universitários do Uruguai (FEUU) teve sua origem em 1929. 
intensificação dar-se-á gradualmente com o fim da ditadura em 1938, mas se intensificará, sobretudo, entre 1948 e 1958, período em que o segundo batllismo intensifica sua influência dentro do Partido Colorado. ${ }^{4}$ Embora tenham existido aspectos que aproximaram o "populismo" uruguaio, argentino e brasileiro (mesmo que a posteriori; Real de Azua, 1984, p. 60), há que se destacar, ao mesmo tempo, diferenças importantes. Entre os pontos em comum, estão as nítidas políticas de industrialização e de redistribuição dos ganhos da guerra, e a política de substituição de importações com forte participação estatal, bem como a mobilização de setores sociais ligados a esse processo e por ele beneficiado.

Por outro lado, ainda que a política de conciliação de classes tenha sido a base sustentadora do projeto de desenvolvimento industrial e social, o deslocamento distributivista uruguaio na direção dos mais pobres não exerceu o mesmo impacto nos setores dominantes como nos seus vizinhos, nem mesmo foi marcado por um forte ímpeto nacionalista (como se passou, sobretudo, na Argentina ou mesmo no Brasil dos anos 1950 e início dos anos 1960). Ademais, como insiste Real de Azua (1984), Luis Batlle era mais um dirigente partidário do que um líder ao estilo de Perón ou Vargas (ou, em menor proporção, Kubitschek-Goulart). Pesa, aqui, a tradição liberal-republicano-radical, sustentada em partidos, o que determinou que a versão "populista" desse país não expressasse as tendências "justicialistas" da Argentina ou "trabalhistas" do Brasil. É importante aqui pontuar que, nesse período (1954), não por acaso, o centro de formação em Serviço Social esteve vinculado ao "Ministerio de Instrucción Pública", absorvido pela "Escuela Universitaria de Servicio Social” (EUSS, 1958-1992).

O fim do neobatllismo e a primeira vitória do Partido Nacional em 1958 culminaram com a formação do Conselho Nacional de Governo

4 Juan José de Amézaga (março de 1943-1947), Luis Batlle Berres (março de 1947-1952, conhecido como o fundador propriamente dito do neobatllismo) e o Conselho Nacional de governo Colorado (março de 1952-1959 — presidido pelo mesmo Luis Batlle Berres). Data desse período (1955) o início da renovação do PCU (Partido Comunista do Uruguai) sob a liderança de Rodney Arismendi (1913-1989), importante quadro do Partido Comunista no país, inclusive para a fundação da Frente Ampla (FA) em 1971. 
liderado pelos nacionalistas - pela primeira vez no país -, a partir de março de 1959. Nota-se, aqui, algo importante que se impõe como traço comum por toda a América Latina: a queda nos valores internacionais dos produtos primários no final dos anos 1950 (sobretudo a carne e a lã - no caso uruguaio), associada ao crescimento dos produtos importados (o que gerou um desiquilíbrio na balança comercial), à manutenção da estrutura latifundiária herdada do período colonial, à desindustrialização, ao processo inflacionário acelerado e à instabilidade do setor financeiro no país, aspectos que enfraqueceram o neobatllismo, desarmaram e inviabilizaram seu projeto de governo. A fórmula apresentada como remédio é conhecida: desestatização, privatização e apoio ao setor agropecuário (Acosta, 2005, p. 72-74). Essa proposta se expressou politicamente no que se convencionou denominar "herrerismo", ou seja, a aliança do ruralismo do caudilho carismático, Benito Nardone, com o líder, Luis Alberto de Herrera, do Partido Nacional.

O período que antecedeu o golpe cívico-militar foi marcado por intensa mobilização envolvendo estudantes, intelectuais, sindicatos, frações das classes médias (onde se inseriam os guerrilheiros tupamaros) e trabalhadores, uma expressiva articulação que influenciou diferentes gerações e níveis sociais. A direita, por sua vez, era composta de setores ruralistas, setor industrial, setores médios urbanos e de serviços, bem como da apatia de parte dos setores populares. A forma como o golpe se deu foi igualmente original: apelou para uma constante articulação com chefes do Executivo civis apoiados pelas Forças Armadas, contou com a participação do presidente colorado-ruralista eleito, Juan María Bordaberry Arocena (março de 1972/setembro de 1973); continuou com o seu sucessor colorado, Pedro Alberto Demicheli Lizaso (que permaneceu pouco mais do que dois meses neste papel); bem como se consolidou com Aparicio Méndez, presidente de fato durante o regime militar (este membro da extrema-direita do Partido Nacional). A função desse governo era explícita: reafirmar o modelo dependente expresso no imperialismo dos Estados Unidos na região com o fim de qualquer projeto 
minimamente independentista, eliminar a oposição, promover controle social das desigualdades e impedir a propagação de culturas e de ações rebeldes fomentadoras de lideranças subversivas (principalmente de orientação marxista-comunista).

A novidade político-partidária no Uruguai foi anunciada em 1971 com a criação da Frente Ampla (FA), que articulou setores progressistas de diversas denominações e manteve-se na oposição durante o regime militar. O processo de redemocratização política a partir de março de 1985 reafirmará a hegemonia dos Partidos Colorado e Nacional com três governos colorados (dois deles liderados por Julio María Sanguinetti 1985/1990 e 1995/2000 - e um por Jorge Batlle - 2000/2005) e um governo blanco (liderado por Luis Alberto Lacalle - 1990/1995). ${ }^{5}$ Tais agremiações já dividiam o espaço político com a Frente Ampla, que cresceu significativamente naqueles 20 anos e estabeleceu uma importante hegemonia progressista entre março de 2005 e março de 2021 com Tabaré Vázquez (duas gestões) e José Mujica. O processo foi novamente interrompido com a eleição de Lacalle Pou e sua posse a partir de março de 2020, o que levou novamente ao Executivo o Partido Nacional a partir de uma ampla frente conservadora que articulou diversas orientações e promoveu uma polêmica coalizão nunca vista antes no Uruguai: blancos e colorados do mesmo lado (além do "Partido Independiente", do "Partido de la Gente e a extrema-direita presente representada pelo "Cabildo Abierto").

Há que se considerar, entretanto, que a troca no comando do Executivo nacional no país não se explica unicamente pelas articulações políticas. Trata-se de um complexo processo imbricado com a economia-política, ou seja, vincula-se decisivamente com projetos políticos que se articulam e se aglutinam para lidar com tensões estruturais afetadas pela economia dependente, neste caso nas condições particulares

5 É importante demarcar que foi nesse período (1992), no conjunto de lutas pela redemocratização do país, que a Escola de Serviço Social foi incorporada à Universidade da República como "Departamento de Trabajo Social de la Facultad de Ciencias Sociales". A consolidação desse processo dar-se-á durante os governos da Frente Ampla (Acosta, 2005; Ortega, 2008; Claramunt, 2018). 
do Uruguai. ${ }^{6}$ A degradação do país, explicitamente em curso a partir de 2013, escancarou-se em 2020 agravada pela crise pandêmica. No âmbito das relações de trabalho, mesmo considerando o caráter mais intervencionista de governos frente-amplistas, uma característica se impôs no mundo e na América Latina: a relativa expansão/manutenção de empregos nos governos progressistas foi acompanhada por sua precarização e intensificação. Durante os 15 anos de Frente Ampla, foram implementadas políticas focalistas de gestão do pauperismo extremo generalizadas por toda a América Latina com base nas orientações do Banco Mundial. Destaque deve ser dado, por exemplo, à criação do “Ministerio de Desarrollo Social (MIDES)" (2005), do “Programa de Atención a la Emergencia Social (PANES)" (2005-2007 — este último responsável pela implementação de políticas focalizadas e seletivas) e do "Plan de Equidad” (2007), ações essas amplamente coerentes com a noção de cidadania neoliberal. Vale ressaltar, ainda, que com importantes medidas de proteção ao trabalhador (Lei de Liberdade Sindical, regulamentação do trabalho doméstico, a jornada de trabalho de oito horas para o trabalhador rural e a retomada dos Conselhos de Salário - que adensou o debate entre o movimento sindical e o Ministério do Trabalho), intensificou-se a precarização do trabalho por meio da regulamentação da terceirização e da subcontratação de trabalhadores.

Destaque deve ser dado, também, ao aprofundamento da política assistencial — na linha aqui destacada — durante o governo de José Mujica, com importante atuação do "Consejo Nacional de Políticas Sociales (CNPS)" e o compromisso com a luta pelas liberdades e pelos direitos humanos: a aprovação da lei do aborto, a descriminalização da maconha, o casamento de pessoas homoafetivas, a inovação na gestão de recursos

6 Seguindo a tradição latino-americana dependente, o que se tem visto no Uruguai são crescimentos abruptos, seguidos de quedas profundas e novos crescimentos cada vez mais baixos e por um curto espaço de tempo. Essa instabilidade igualmente impactou o mundo do trabalho, sempre no sentido de tensionar na direção de uma gestão da lei geral da acumulação capitalista tendencialmente em favor do capital constante em detrimento do capital variável. Sobre isso, consultar Silva (2021) e Real GDP Growth (2020). 
humanos, expansão e aprofundamento das políticas de saúde sexual e reprodutiva, mental e de drogas (Claramunt, 2018). É importante salientar, ainda, a ênfase oferecida à política educacional, entre elas a substancial expansão, o aprimoramento e a descentralização da Universidade da República, inclusive com melhores condições materiais e humanas. De qualquer forma, as políticas estimuladas pela Frente Ampla atuaram no sentido de articular as tradicionais políticas universalistas com as mais focalizadas, ainda que elas tenham se dedicado substancialmente à expansão destas últimas.

Com base de sustentação ruralista, ampla composição política (inclusive de extrema-direita) e um discurso que reivindicou segurança às famílias uruguaias (estímulo ao porte de armas, fortalecimento das ações policiais contra o crime e o tráfico de drogas e reforma do sistema prisional), o governo de Lacalle Pou pregou austeridade e redução do déficit fiscal, corte dos gastos públicos, estímulos à iniciativa privada, otimização e modernização do Estado e contrarreforma previdenciária. Reconfigurou os "Consejos de Salarios" criados em 1943 pelo neobattlismo retomados no primeiro governo de Sanguinetti e recriados pela Frente Ampla (depois de um longo período, desde o governo de Lacalle Herrera, pai de Lacalle Pou, em que não foram convocados), incluindo representantes dos trabalhadores rurais, particulares e dos funcionários públicos, estimulando amplamente o que se caracterizou como "modernização": aumento do mercado de trabalho por cooperação e negociação direta entre patrões e empregados, amplo estímulo ao uso de tecnologias no âmbito do trabalho, essencialmente flexibilizado e empreendedor, além de priorizar o aspecto da produtividade nas negociações coletivas.

Em pleno período pandêmico, Lacalle Pou enviou ao Congresso - já em abril de 2020 - o seu mais importante Projeto de Lei denominado "Ley de Urgente Consideración" (LUC), visto como de extrema importância para o projeto governamental. Tal proposta de lei, aprovada em 2020 pelo Congresso e pelo Senado sem alterações substanciais, redimensionou na perspectiva já descrita e por meio de 476 artigos — importantes temas, tais como educação, saúde, trabalho, economia e meio ambiente, como 
também deu grande ênfase à área de segurança. Isso tem ocorrido não sem a forte resistência sindical e de movimentos sociais progressistas, que conseguiram as assinaturas necessárias para convocar um referendum para tentar revogar 135 artigos da lei.

\section{O Serviço Social no Uruguai e a sua fração mais crítica}

Uma indagação se impõe neste momento: como situar o debate crítico do Serviço Social nesse complexo contexto? Há de se destacar que a renovação do Serviço Social no Uruguai dos anos 1960 e sua particular inserção no processo de reconceituação latino-americano contaram com um contexto que reorganizou política e economicamente o país a partir da segunda metade dos anos 1950. Isso acirrou as tensões no Uruguai, questionou a tradicional hegemonia colorada, suas bases historicamente centradas em ações, proposições e políticas marcadas por amortecer conflitos estruturais. É nesse contexto que propostas amplamente liberais foram adensadas sob a liderança do Partido Nacional entre 1959 e 1967, bem como se aprofundou a polarização que culminou com um importante acontecimento no âmbito da classe operária: a unificação sindical (1966). A polarização social, então, se consolidou organizada em dois blocos principais no país: por um lado, amplo movimento estudantil (também unificado por meio da "Federación de Estudiantes Universitarios del Uruguay"), o movimento operário e importantes setores das classes médias urbanas; por outro, os setores tradicionais-conservadores liderados pelo Partido Nacional pela primeira vez na história do país. Junta-se a isso um complexo cenário internacional marcado pela Guerra Fria, pela intervenção dos Estados Unidos na região e pela Revolução Cubana e seus desdobramentos por toda a América Latina.

No âmbito do Serviço Social, uma tradição progressista e amplamente diversa, fortemente militante, se formou e paulatinamente se consolidou. Articularam-se, aqui, a partir desse complexo cenário, diversos elementos que constituíram a base que sustentou a gênese, a consolidação 
e o desenvolvimento da fração mais crítica do Serviço Social uruguaio, não sem desconsiderar traços sócio-históricos explicitamente republicanos-liberais-democráticos, laicos, de forte inspiração iluminista francesa, com a valorização de certo tipo de "cidadania hiperintegradora" e com forte intervenção estatal. Essa ampla base social de sustentação progressista atuou decisivamente na criação da Frente Ampla em 1971, bem como foi enriquecida por setores colorados e blancos mais progressistas, que abandonaram sua tradicional base e ajudaram a criar importante unidade que também se expressou no Serviço Social uruguaio.

A resistência contra a ditadura militar foi hegemonicamente apoiada pelas(os) assistentes sociais uruguaias(os), na sua ampla diversidade. Suas diferentes tendências, embora debatessem, convergiam em relação à resistência ao regime cívico-militar e à repressão ao centro de formação (Acosta, 2005, p. 244-247), considerando: a) a perda da autonomia da “Escuela Universitária de Servicio Social” em 1973; b) a remoção de suas autoridades legalmente constituídas com a nomeação de interventores que tinham a determinação de fechar a unidade de ensino; c) a exigência de que funcionários da escola, a partir de 1976, assinassem a chamada "declaração de fé democrática” (!) jurando a não participação em organizações, ações e eventos considerados subversivos, fato que gerou o desligamento de diversos docentes; d) e a forte repressão ao movimento estudantil que conseguiu iniciar sua reorganização a partir de 1979 - ainda que clandestinamente - por meio do Centro de Estudantes Universitários de Serviço Social (mais abertamente presente a partir de 1983 com o fortalecimento do movimento sindical). É importante ressaltar, ainda, a fundação da ADASU (Asociación de Asistentes Sociales del Uruguay) em outubro de 1981 (em pleno regime cívico-militar), produto dessa ampla reorganização e resistências envolvendo profissionais de diferentes orientações políticas e teóricas no âmbito da profissão naquele momento histórico.

Outro importante acontecimento acentuou e marcou decisivamente a tendência progressista do Serviço Social no Uruguai: a "Escuela Universitária de Servicio Social” foi incorporada pela Faculdade de Ciências 
Sociais a partir de 1992, após amplo debate sobre o sentido que deveria ser adotado na formação de profissionais da área, debate esse já influenciado pelos impactos da reestruturação produtiva na América Latina e no Uruguai nos anos 1990 (portanto, um momento histórico distinto dos anos 1960/1970). Vale destacar a importância de inserir o Serviço Social como disciplina com o mesmo status atribuído às áreas das ciências sociais, a elas associada como área particular, ressaltando a relação dessa profissão com a "questão social", suas múltiplas refrações (no campo das políticas sociais), abrindo a possibilidade de formar assistentes sociais intelectuais, ou seja, produtores de conhecimento como parte de uma área de conhecimento. A criação de quadros acadêmicos favoreceu o adensamento teórico, possibilitando que docentes-assistentes sociais se dedicassem integralmente à produção de conhecimento no campo das Ciências Humanas Sociais. Esse salto consolidou-se com o primeiro mestrado feito em parceria com o Programa de Pós-Graduação em Serviço Social da Universidade Federal do Rio de Janeiro (UFRJ) e, posteriormente, como um programa de mestrado autônomo e o doutorado com saída em Trabajo Social como parte da Faculdade de Ciências Sociais. Junta-se a isso o lastro acumulado pelo Serviço Social no processo de resistência ao regime cívico-militar e durante a retomada da democratização política do país a partir de 1985. Portanto, a dissolução da EUSS e sua recriação vinculada à Faculdade de Ciências Sociais da Universidad de La República significou o fim do ciclo dos anos 1960 e a reorganização das tendências teórico-práticas prioritariamente articuladas àquele contexto, submetendo à crítica projetos de inspiração desenvolvimentista, de orientação sociológico-modernizadora e de educação popular (Acosta, 2005, p. 255-262).

Os anos de expansão contínua e consolidação da profissão ocorreram nessa etapa, culminando com os 15 anos de governo da Frente Ampla a partir de 2005. Esse processo marcou uma profunda alteração na esfera estatal, sua modernização, bem como a ampliação de políticas assistenciais com impactos no espaço sócio-ocupacional dessa profissão e no campo da gestão do pauperismo relativo e absoluto. Ofereceu, ainda, um leque de temas de estudo à intelectualidade da área, fomentando 
produções teóricas articuladas às políticas sociais implementadas pelo Estado uruguaio a partir dos anos de 1990 e 2000, políticas essas vinculadas às estratégias governamentais orientadas pelo Banco Mundial, amplamente utilizadas na América Latina com diferentes denominações.

A expansão do mercado de trabalho - incluindo assistentes sociais - deu-se também por meio de sua precarização, sua brutal intensificação, o que causou — no geral - a necessidade de esses (as) profissionais obterem mais do que uma fonte geradora de recursos (Claramunt, 2018). Mais do que isso, houve alterações substanciais na vida do povo uruguaio por meio de propostas que passaram a articular políticas universais fundamentais e programas de gestão do pauperismo extremo. Esta reengenharia também afetou as universidades, seja para criar e consolidar importantes funções docentes em condições nunca vistas no país, seja para reestruturar esses papéis no interior da instituição universitária (Bentura; Vecinday, 2019, p. 225).

Produto desse amplo contexto e das intensas lutas travadas nas condições particulares do país, emergiu uma diversa tradição teórica progressista situada, sobretudo, nas instâncias acadêmicas, especificamente na Universidad de La República. Ela possui, indubitavelmente, um eixo-tema estruturante: $a$ análise do objeto concreto com a qual a profissão lida cotidianamente, priorizando o estudo das políticas sociais, seguindo a tradição "hiperintegradora" de programas e projetos sociais historicamente presentes no país. Diversifica-se e refrata-se, então, em diferentes temas de estudo e linhas teóricas progressistas-libertárias igualmente heterogêneas. Articula-se politicamente com a tradição político-partidária mais progressista no país, especificamente a Frente Ampla e suas diversas frações internas.

A partir dessa base, uma ampla, diversa e atualizada intelectualidade tem se constituído na relação com as forças progressistas. São exemplos importantes e heterogêneos: a) Laura Vecinday com estudos originais no campo da assistência e da proteção social (Bentura; Vecinday, 2019; Venciday; Bentura, 2019); b) Alejandro Mariatti e suas pesquisas sobre a mundialização da economia capitalista, tecnocratização, ativação do 
mercado de trabalho e as transformações do trabalho no Uruguai (Bentura; Mariatti, 2018; 2016; Mariatti, 2020); c) Adela Susana Claramunt e suas importantes análises sobre a realidade do Serviço Social no Uruguai na atualidade (Claramunt, 2018); d) José Pablo Bentura e o estudo sobre as políticas sociais no contexto atual da acumulação capitalista, o papel do Estado, nisso o Serviço Social (Bentura; Mariatti, 2018; Bentura et al., 2016); e) Alejandro Casas e a análise de importantes categorias gramscianas extraídas da realidade latino-americana e uruguaia: Estado, sociedade civil, intelectuais, moral, direção social-cultural estratégica, correlação de forças, cultura e revolução passiva (como transformismo Casas, 2018; Casas, 2019); f) Elisabeth Ortega Cerchiaro e suas pesquisas sobre a relação entre medicina e religião debatendo, nesse contexto, com base na análise genealógica de Foucault, as transformações do Serviço Social no Uruguai nos 20 anos que antecederam a ditadura cívico-militar no país (Ortega, 2011); g) Carolina González Laurino e de Sandra Leopold Costábile, com produções conjuntas ou próprias, destacam as recentes transformações no modelo de proteção social uruguaio, com especial ênfase no debate da infância e da juventude (Leopold Costábile; González Laurino, 2015; González Laurino; Leopold Costábile, 2018; Leopold Costábile, 2014; González Laurino, 2021); h) Silvia Rivero com seus estudos sobre as novas formas de gestão das políticas sociais, em associação com as chamadas organizações da sociedade civil (Rivero, 2013); i) Mónica de Martino e suas pesquisas sobre os sistemas de proteção social, as famílias, os processos de economização do social, adensados pelo discurso da vulnerabilidade social e os debates sobre gênero, com destaque para o estudo das políticas sociais dedicadas a segmentos e viabilizadas pelo Estado. Sua originalidade está, todavia, em uma postura analítica que aponta o que a autora entende com sendo os limites de Marx e dos marxismos no debate com Foucault e, mais recentemente, com Sartre (De Martino, 2020; 2010; 2009).?

Carlos Montaño, Luis Acosta, Gabriela Lema e Alejandra Pastorini Corleto, embora tenham vida profissional no Brasil, também possuem importante produção na área dentro e fora do Uruguai. 


\section{Considerações finais}

A ampla organização de resistência à ditadura cívico-militar, o processo de redemocratização política no país e o fim da intervenção na universidade foram decisivos para que a "Escuela Universitaria de Servicio Social" passasse a compor a Faculdade de Ciências Sociais da Udelar por meio de um Departamento de Trabajo Social. O que até então era predominantemente um processo de mobilização político-militante - adensado pela renovação do Serviço Social no Uruguai no interior do processo de reconceituação - alçou outros patamares, na medida em que profissionais da área de Serviço Social passaram a ocupar o espaço universitário, adensaram a formação teórica, começaram a realizar pesquisas e produzir conhecimento. Esse processo também foi de grande valia para que os(as) assistentes sociais ampliassem sua interlocução para além das fronteiras profissionais, na área de Ciências Sociais, criando as condições objetivas para um debate mais denso e maduro entre a teoria social e o legado objetivamente construído pela profissão durante anos de conservadorismo, renovação, organização, resistência, maior proximidade com instâncias acadêmicas e formativas, e seu adensamento e consolidação como área de conhecimento.

Após anos sucessivos de lutas e conquistas empreendidas pelo Serviço Social uruguaio, sua explícita expansão como profissão e consolidação como área de conhecimento no campo das Ciências Humanas e Sociais - na íntima relação com as conquistas do país - um período de estagnação parece se impor, fruto da ofensiva do capital sobre o trabalho a partir das condições determinadas pelo imperialismo e pelo capitalismo dependente reorganizados na região no processo de crise estrutural do capital. Nisso, certamente, aspectos particulares que marcam a história recente do país, com o explícito revigoramento da direita e da extrema-direita uruguaia. Retrocessos no campo das políticas sociais (não apenas as de caráter mais universal), precarização nas condições de trabalho dos(das) assistentes sociais (dentro e fora das universidades) e dificuldades relacionadas às condições necessárias para a produção de 
conhecimento autêntico e comprometido com a crítica radical tendem a se aprofundar. Contra isso, as frações progressistas do Uruguai (com elas, as da profissão) possuem uma tradição de que jamais podem abdicar: unidade sindical, importante tradição laico-republicana e organização partidária e popular. Mas isso não solitariamente: precisam expressar projetos e alternativas de resistência mundial e latino-americana.

\section{Referências}

ACOSTA, Luis. O processo de renovação do Serviço Social no Uruguai. 2005. Tese (Doutorado) — Universidade Federal do Rio de Janeiro, Rio de Janeiro, 2005.

BENTURA, José Pablo; MARIATTI, Alejandro. La integralidad de las funciones universitarias en el contexto de mundialización de la economía. Apuntes desde el Trabajo Social. Revista Fronteras, Montevideo: Departamento de Trabajo Social, n. 9, mar. 2016.

BENTURA, José Pablo; MARIATTI, Alejandro. La metamorfosis del trabajo y los procesos de activación. Serviço Social @ Sociedade, São Paulo: Cortez, n. 131, p. 89-108, jan./abr. 2018.

BENTURA, José Pablo; VECINDAY, Laura. Desafios, obstáculos e tensões do Serviço Social uruguaio no início do século XXI. In: YAZBEK, Maria Carmelita; IAMAMOTO, Marilda Villela (org.). Serviço Social na história: América Latina, África e Europa. São Paulo: Cortez, 2019. p. 217-239.

BENTURA, Pablo et al. Exigência de condicionalidades: significados, alcances e controvérsias no debate. In: SILVA E SILVA, María Ozanira da (org.). O mito e a realidade no enfrentamento à pobreza na América Latina: estudo comparado de programas de transferência de renda no Brasil, Argentina e Uruguai. São Paulo: Cortez, 2016. p. 147-170.

CAETANO, Gerardo. La República Batllista. Montevideo: Ediciones de La Banda Oriental, 2015. (Colección HR).

CASAS, Alejandro. Luchas por la hegemonía y bloques históricos en el Uruguay contemporáneo y en la actual coyuntura. In: CASAS, Alejandro (org.). Sujetos colectivos populares, mundo del trabajo y territorios: estudios en el Uruguay progresista. Montevideo: Área Académica de Liberación, 2018. p. 6-40.

CASAS, Alejandro (org.). Sujetos colectivos populares, mundo del trabajo y territorios: estudios en el Uruguay progresista. Montevideo: Área Académica de Liberación, 2019.

CERCHIARO, Elizabeth Ortega. El Servicio Social y los procesos de medicalización de la sociedad uruguaya en el periodo neobatllista. Montevideo: Trilce, 2008. 
CLARAMUNT, Adela S. Los trabajadores sociales en el Uruguay en la última década: sus espacios socio-ocupacionales y condiciones de trabajo. 2018. Tese (Doutorado) Universidad de la República, Montevidéu, 2018.

DE MARTINO, Mónica. Familias y protección social. Diálogos entre el campo del marxismo y Foucault. Revista de Políticas Públicas, São Luís: UFMA, v. 13, p. 43-53, 2009.

DE MARTINO, Mónica. Marxismo, género e historia social. Puntos y contrapuntos. Revista de Políticas Públicas, São Luís: UFMA, v. 14, p. 39-46, 2010.

DE MARTINO, Mónica. Sobre el método progresivo-regresivo sartreano: una perspectiva para el trabajo social. Katálysis, Florianópolis, v. 23, n. 3, p. 590-600, dez. 2020.

DE MARTINO, Monica Solange; ORTEGA, Elisabeth. Passado e presente do Serviço Social uruguaio. Sobre as teses de precarização. In: YAZBEK, Maria Carmelita; IAMAMOTO, Marilda Villela (org.). Serviço Social na história: América Latina, África e Europa. São Paulo: Cortez, 2019. p. 188-216.

FERNANDES, Florestan. Capitalismo dependente e classes sociais na América Latina. São Paulo: Global, 2009.

GONZÁLEZ LAURINO, Carolina. Sentidos, prácticas y modificaciones en los informes técnicos del sistema penal juvenil uruguayo. Tempo Social, v. 33, n. 1, p. 203-224, 2021.

GONZÁLEZ LAURINO, Carolina; LEOPOLD COSTÁBILE, Sandra. Transformaciones en la matriz de protección uruguaya a inicios del siglo XXI. Textos \& Contextos, Porto Alegre, v. 17, n. 1, p. 52-66, 2018.

KATZ, Claudio. A teoria da dependência: 50 anos depois. São Paulo: Expressão Popular, 2020.

LEOPOLD COSTÁBILE, Sandra. Los laberintos de la infancia: discursos, representaciones y crítica. Montevideo: Universidad de la República Uruguay; CSIC, 2014.

LEOPOLD COSTÁBILE, Sandra; GONZÁLEZ LAURINO, Carolina. Los riesgos de la individualización en el nuevo modelo de protección social uruguayo: el caso del Programa Jóvenes en Red. Sociedade em Debate, v. 21, n. 1, p. 211-254, 2015.

MARIATTI, Alejandro. El proceso de transformación laboral en Uruguay. Textos $\diamond$ Contextos, Porto Alegre, v. 19, n. 1, e38359, 2020.

MARINI, Ruy M. América Latina, dependencia y globalización. Bogotá: Clacso; Siglo del Hombre Editores, 2008.

ORTEGA, Elizabeth. El Servicio Social y los procesos de medicalización de la sociedad uruguaya en el período neobatllista. Montevideo: Trilce, 2008.

ORTEGA, Elizabeth. Medicina, religión y gestión de lo social: un análisis genealógico de las transformaciones del Servicio Social en el Uruguay (1955-1973). Montevideo: Udelar, 2011. 
REAL DE AZUA, Carlos. Uruguay, ¿una sociedad amortiguadora? Montevideo: Ediciones de La Banda Oriental, 1984. (Colección Estudios sobre la Sociedad Uruguaya, número 3).

REAL GDP GROWTH. International Monetary Fund. [2020]. Disponível em: https://www. imf.org/external/datamapper/NGDP_RPCH@WEO/OEMDC/ADVEC/WEOWORLD. Acesso em: 28 jul. 2020.

RIVERO, Silvia. De la acción política a la gestión: sociedad civil en movimiento. 2013. Tese (Doutorado) - Facultad de Ciencias Sociales, Universidad de la República, Montevideo, 2013.

SILVA, José Fernando S. América Latina: capital e devastação social. Katálysis, Florianópolis: UFSC, v. 24, n. 1, 2021.

VENCINDAY, Laura; BENTURA, José Pablo (org.). Entre la asistencia y la activación: intervenciones sobre la pobreza en el Uruguay progresista. Montevideo: Udelar; Grupo de Estudios sobre Sistemas de Protección Social, Prácticas Institucionales e Profesionales, 2019.

\section{Sobre os autores}

José FeRnando SiqueIRA da Silva - Livre-docente em Serviço Social pela Universidade Estadual Paulista (Unesp). Pós-doutor em Serviço Social pela Universidade Nacional de La Plata (UNLP - Argentina) e Universidade da República (Udelar - Uruguai). Professor associado. Bolsista Produtividade do CNPq desde março de 2009 (nível 2). Coordenador do Grupo de Estudos e Pesquisas Marxistas (Gepem).

E-mail: jose.siqueira-silva@unesp.br

José Pablo Bentura - Doutor em Ciências Sociais pela Faculdade de Ciências Sociais (FCS) da Universidade da República (Udelar - Uruguai). Docente e pesquisador. Pesquisador do Sistema Nacional de Investigadores da Agência Nacional de Investigação e Inovação (ANII).

E-mail: pbentura@gmail.com 